\title{
Teaching as regulation and dealing with complexity
}

\author{
H. P. A. Boshuizen ${ }^{1,2}$
}

Received: 14 May 2016/ Accepted: 18 May 2016/Published online: 30 May 2016

(C) The Author(s) 2016. This article is published with open access at Springerlink.com

\begin{abstract}
At an abstract level, teaching a class can be perceived as one big regulation problem. For an optimal result, teachers must continuously (re)align their goals and subgoals, and need to get timely and valid information on how they are doing in reaching these goals. This discussion describes the specific difficulties due to the time characteristics of the multiple, simultaneous events happening in classrooms, the lack of information on results, and the validity and usability of the shared knowledge-base. The contribution of the five articles in this special issue is discussed.
\end{abstract}

Keywords Regulation - Complexity · Information on results · Professional knowledgebase $\cdot$ Modes of cognition $\cdot$ Teacher expertise

Building teacher expertise requires many years of training and experience in which one learns to handle simultaneous and multiple tasks (see Lachner et al., this issue). This simultaneity and multiplicity (Doyle 1977) is not unique to teaching but specific features and combinations of features make it especially complex. Teaching a class can be seen as one big regulation problem (Cronin and Gonzalez 2007): multiple goals have to be pursued, while disturbances have to be minimised using different kinds of steering instruments. These multiple, coordinated goals vary along several dimensions: e.g., academic goals (per lesson, per course, per curriculum) and conducive goals (safety, quiet environment, good working relation with group and individuals). These goals, their hierarchy, and the quality of the instruments teachers have at their disposal determine the outcome of such a regulation problem. In the following paragraphs I'll discuss a couple of factors that

H. P. A. Boshuizen

Els.Boshuizen@ou.nl

1 Welten Institute, Open University of the Netherlands, PO Box 2960, 6401 DL Heerlen, The Netherlands

2 Faculty of Education, University of Turku, 20014 Turku, Finland 
affect the smooth regulation of complex systems in teaching, i.e., the time scales at which events take place, information on results needed for regulation, and teachers' tools.

\section{Time-scales: simultaneity and multiplicity}

A class is not a flock of sheep that-led by the herder-moves collectively in one direction. Individuals within a class have their own academic and social goals, motivation, prior knowledge, etc. As a result of this diversity, a teacher might give an explanation (of an element of the immune system, for instance) at one specific moment, while half of the students (seem to) listen attentively, while one student raises her hand (A), two students whisper (B \& C), one dives down to check her bag (D), one sneezes loudly and repeatedly (E), etc. The teacher might judge this situation as 'potentially disturbed attention' of the class, and to prevent this takes a step in the direction of student $\mathrm{D}$, meanwhile signaling $\mathrm{A}$ that her hand has been noticed, mentioning the role of sneezing as the first line of defence of the immune system, and-while monitoring students B to E-call student A, before returning to the explanation. This is what teachers do continuously while teaching: they monitor and judge behaviour and progress at different levels of the goal hierarchy, and act accordingly, in order to make their students reach the goals set.

These teacher actions occur simultaneously but concern events taking place at different time scales. Some events just take a couple of seconds, like sneezing, or picking a pencil from a bag, while others take much longer like the teacher's explanation. Furthermore, events can take different courses. Some are self-delimiting while others can ignite a chain of undesirable new events. Eraut (1994) described actions during such events in term of the following four processes: (1) reading the situation, which requires constant monitoring in classroom situations keeping the active goals in mind, (2) decision making, i.e., diagnosis and choice from an action repertoire, (3) the overt action, and (4) metacognitive awareness, reflection and evaluation of progress of the event and outcome of the action. The different time scales of the events taking place within one situation require different modes of cognition: instant events require reflexive action (if any), rapidly evolving events ask for intuitive decision making and actions, while 'slow' events allow a deliberative and analytic approach. As multiple events take place within one situation, these actions must be orchestrated as the teacher in our example does.

Expertise research in other domains, especially in sports where multiple instant and rapid events have to be dealt with, confirms that experts can detect and correct or react to small changes hence prevent that full-blown events occur (see Williams et al. 2004). Accordingly, experts can coordinate multiple goals and simultaneously monitor their fulfilment, while beginners may need all their skill to fulfil only one goal at a time (Wagenaar 2008).

\section{Information on results}

Apart from clear goals, regulation of teaching and learning processes requires information on results. Have the (sub)goals been reached? If not, did I overshoot or undershoot? Or was one goal reached at the expense of another? Information on results requires valid and timely measures, preferably not only on the outcomes but also on the process. Yet, what may sound as a platitude is in natural practice a condition that is often not met (Shanteau 
1992). Results remain unknown because of lacking instruments, because of distorted links between process, performance and outcome, and because people often have attribution patterns of success and failure that are not helpful for learning (Weiner 2014).

Tests and exams could fulfil this role. However, many teachers see them as indicators of students' success and failure and not of their own. Especially the feedback value of end-ofterm tests is minimal, due to their timing (see Black and Wiliam 1998). More flexible, adaptive, formative (self) assessment methods applied during learning can identify the gap between goals stated and present status, and suggest resources to teachers and learners for remediation.

\section{The teacher's tools: the professional body of knowledge}

Similar to other professional domains, education shows a tendency toward building a proven and shared knowledge-base. Contributions come from teachers' action research, (design) experiments, review studies, and reviews of reviews (Hattie 2008).

Yet, utilization of knowledge from general research findings is not a self-evident task. Findings must be further developed into practices and skills that fit the specific classroom, group of students, and/or the subject matter involved. As long as that further development is left to the individual teacher the resulting skill is at best idiosyncratic. A format for knowledge utilisation in which practice development is the joint responsibility of a group of teachers, in cooperation with the researcher might be more fruitful in building a shared, well underpinned professional knowledge base (Vermeulen 2014).

\section{What this special issue contributes}

The specific difficulties described above are inherent to teaching and the way teaching is organised. They provide difficulties for everyone in the profession, to experts and novices. Yet, experts have developed practices, skills or routines that are helpful to deal with these difficulties.

Regarding timescales, simultaneity and multiplicity, Wolff et al.'s study (this issue) gives us more insight into teachers' reading the situation and detection of instant and rapid events Eraut 1994). They found that novices' are distracted by phenomena that may not even be relevant for the goals pursued, whereas experts have developed monitoring strategies that may help them identify upcoming complications before these have become full-blown. Stürmer et al.'s study adds that the skill to predict the course of events develops as a result of training and experience, but warns that there are remarkable individual differences. These outcomes may help understand the anatomy of experienced teachers' schemata underlying their skill in smoothly running a classroom, and develop accelerated roads toward expertise (Fadde 2009).

The study by Furtak et al. (this issue) on the development of formative assessment skills shows the importance of information about results. Over the course of 3 years, teachers improved their practices and therefore could procure better information on the results of their teaching, which in turn led to better learning of students. Their findings also show that feedback quality appears to increase during the training (a very powerful teaching tool, Hattie 2008). Yet, crucial to the teacher's improvement was their improved skills in 
eliciting and interpreting information on students' progress. Based on this information, teachers could adapt their teaching resulting in better learning.

Where Wolff et al. used the term 'vision' in the sense of 'viewing', Stürmer et al. explicitly related it to shared professional knowledge and values. The results of both Lachner and Nückles (this issue), and Herppich et al. (this issue) remind us that that didactic knowledge of what is effective and why should always be considered and further developed in combination with the specific field involved. Herppich et al. found that pedagogical experts revert to explanations when tutoring in a biological domain and generate less deep learning than tutors with less pedagogical expertise, who happened to be more interactive and rather scaffold their tutee's learning. These findings contradict other empirical findings on the role of explanatory knowledge in learning (Lachner and Nückles, this issue; Mylopoulos and Woods 2014). This contradictory cluster of findings can result from differences between the domains, or from ingrained expert practices that turn counterproductive in new situations (tutoring was equally new to experts and non-experts). Its resolution can be sought in further experimentation, but it might be more fruitful when innovative practices for knowledge utilisation are applied, in which the professional needs of the teachers can meet the academic curiosity of the researchers. Careful, long-term design studies, such as the one by Furtak et al., show that co-creation of practices can improve the utilisation of valid pedagogical/didactic knowledge, and support teachers to include that in the schemata that form the heart of the skilful and coordinated perception of and action in of classroom situations.

Open Access This article is distributed under the terms of the Creative Commons Attribution 4.0 International License (http://creativecommons.org/licenses/by/4.0/), which permits unrestricted use, distribution, and reproduction in any medium, provided you give appropriate credit to the original author(s) and the source, provide a link to the Creative Commons license, and indicate if changes were made.

\section{References}

Black, P., \& Wiliam, D. (1998). Assessment and classroom learning. Assessment in Education: Principles, Policy \& Practice, 5(1), 7-74.

Cronin, M. A., \& Gonzalez, C. (2007). Understanding the building blocks of dynamic systems. System Dynamics Review, 23(1), 1-17.

Doyle, W. (1977). Learning the classroom environment: An ecological analysis. Journal of Teacher Education, 28(6), 51-55.

Eraut, M. (1994). Developing professional knowledge and competence. RoutledgeFalmer: New York.

Fadde, P. J. (2009). Instructional design for advanced learners: Training expert recognition skills to hasten expertise. Educational Technology Research and Development, 57(3), 359-376.

Hattie, J. (2008). Visible learning: A synthesis of over 800 meta-analyses relating to achievement. New York: Routledge.

Mylopoulos, M., \& Woods, N. N. (2014). Preparing medical students for future learning using basic science instruction. Medical Education, 48(7), 667-673.

Shanteau, J. (1992). The psychology of experts: An alternative view. In G. Wright \& F. Bolger (Eds.), Expertise and decision support (pp. 11-23). New York: Plenum Press.

Vermeulen, M. (2014). Knowledge utilisation (KU) in education: Lessons learned from other social sciences. In Paper presented at the EAPRIL conference, Nicosia, Cyprus, November 2014.

Wagenaar, A. (2008). What and how students learn from experience. PhD Thesis, Maastricht University.

Weiner, B. (2014). The attribution approach to emotion and motivation: History, hypotheses, home runs, headaches/heartaches. Emotion Review, 6(4), 353-361.

Williams, A. M., Ward, P., Smeeton, N. J., \& Allen, D. (2004). Developing anticipation skills in tennis using on-court instruction: Perception versus perception and action. Journal of Applied Sport Psychology, 16(4), 350-360. 